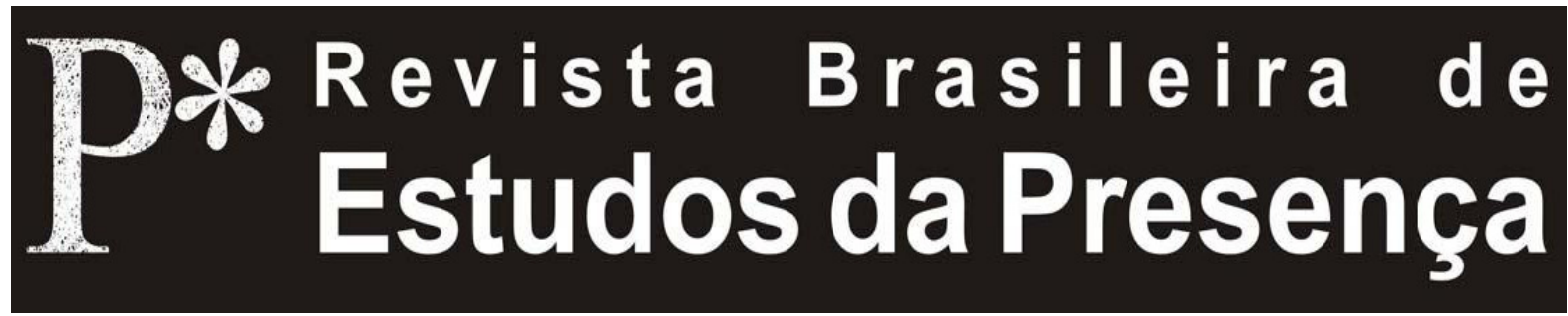

DOI - http://dx.doi.org/10.1590/2237-266036945

ISSN 2237-2660

\title{
Mapas e Caminhos: práticas corpóreas e transculturalidade
}

Fernando Antonio Mencarelli

Universidade Federal de Minas Gerais - UFMG, Belo Horizonte, MG, Brasil

RESUMO - Mapas e Caminhos: práticas corpóreas e transculturalidade - O interesse de Grotowski por práticas de origens culturais diversas ganhou especial destaque na passagem da fase Parateatral (1969-1978) para aquela denominada Teatro das Fontes (1976-1982). Buscamos neste artigo refletir sobre como se deu e como se concebeu essa experiência em sua dimensão transcultural a partir de práticas corpóreas presentes em diferentes culturas que se transmitem como conhecimento corporificado.

Palavras-chave: Transculturalidade. Corpo. Práticas. Cultura Ativa. Grotowski.

ABSTRACT - Maps and Paths: bodily practices and transculturality - Grotowski's interest in practices from different cultures had special importance during his transition from the Paratheatre phase (1969-1978) to the so-called Theatre of Sources (1976-1982). This article deals with the way this occurred and how was conceived this experience in its transcultural dimension based on bodily practices present in different cultures and which are transmitted as embodied knowledge.

Keywords: Transculturality. Body. Practices. Active Culture. Grotowski.

RÉSUMÉ - Les Cartes et les Chemins: pratiques corporelles et transculturalité L'intérêt de Grotowski pour les pratiques de différents milieux culturels s'est développé dans le passage de la phase Parathéâtrale (1969-1978) à celle qu'on appelle Théâtre des Sources (1976-1982). Cet article explique cette évolution et la façon dont cette expérience a été conçue dans sa dimension transculturelle, à partir des pratiques corporelles présentes dans différentes cultures et transmises en tant que connaissance incarnée.

Mots-clés: Transculturalité. Corps. Pratiques. Culture Active. Grotowski. 
Em uma conferência na Shangai Theatre Academy, em dezembro de $2011^{1}$, Mario Biagini, diretor associado do Workcenter of Jerzy Grotowski and Thomas Richards, referia-se à importância de reconhecer os modelos, as imagens, os mapas corporais que mobilizamos a partir de nossa cultura quando experimentamos práticas corporais criadas em outros contextos. A observaçáo é resultado de anos de experiências no Workcenter com práticas performáticas que foram pesquisadas por Grotowski desde o início de sua carreira, mas especialmente a partir da fase Parateatral, e foi feita em um contexto especial em que o grupo desenvolvia suas práticas com alunos de uma das principais escolas de formaçáo de atores na China. O risco, acredito, seria de os mapas mentais preexistentes acionados no processo da experiência corpórea atuarem como acessórios por vezes inadequados, por se sobreporem à própria experiência ao sugerir caminhos imaginados.

É importante lembrar que para o mesmo corpo cada cultura gerou mapas mentais distintos, projetando sobre ele uma série de perspectivas sobre os processos e trocas; assim como uma visão dinâmica do que se denomina corpo, mente, espírito ou processos interiores, com suas semelhanças e diferenças.

Quando nos aproximamos dos aspectos mais complexos do trabalho supostamente 'interior', evito na medida do possível qualquer verbalização. Evito por exemplo verbalizar a questão dos centros energéticos que podemos localizar no corpo. E esclareço "que podemos localizar no corpo" porque isso náo está nada claro. Dizem respeito ao campo biológico ou a um campo mais complexo? Os mais conhecidos são os centros segundo a tradição da yoga, os que se chamam chacras. Está claro que se pode descobrir de maneira precisa a presença de centros energéticos no corpo, desde os que estão maîs vinculados à sobrevivência biológica, aos impulsos sexuais, etc., passando por centros cada vez mais complexos, (ou é preciso dizer mais sutis?) e que isso seja sentido como uma topografia corporal cujo mapa se pode desenhar claramente (Grotowski, 1997a, p. 122-123).

Os substratos culturais que comportam maior diversidade entre si também geraram diferentes topografias do corpo. Mesmo dentro de uma linha de desenvolvimento cultural podemos observar como a ideia de um centro do corpo pode se transformar (do fígado ao coração ou ao cérebro). A medicina chinesa condensa um conhecimento sobre o corpo em um mapa bastante diverso dos atlas corporais que a medicina chamada ocidental organizou.

Por isso, quando pensamos em cruzamentos culturais precisamos pensar em distintas concepçôes, ou geografias de corpo. $\mathrm{O}$ 
encontro entre essas práticas de cultura pode ter o mesmo impacto que a aprendizagem de uma língua ou de um pensamento, mas precisa ser pensado como território de encontro, aprendizagem e alargamento de percepção.

Umberto Eco fala dos livros que carregamos quando nos aproximamos do novo, do diferente em outras culturas: "A influência desses livros de referência é tal que os viajantes, quaisquer que sejam suas descobertas e as realidades percebidas, vão tudo interpretar e tudo explicar em função dessas obras" (Eco, 2011, p. 310). Também podemos dizer algo semelhante dos mapas mentais corporais e de suas bases filosóficas quando tratamos das experiências corporais trabalhadas no campo transcultural.

Ainda que as ciências cognitivas avancem sobre a questão desses processos, elas ainda caminham em direção a perguntas que emergem de sua base filosófica ocidental. A forma como os sistemas de conhecimento tradicionais, indiano, chinês, africano ou indígena americano, tratam desses temas projetam as discussóes em outros planos, passíveis neste momento de serem tratadas especialmente no campo da cultura.

Se pensarmos junto com alguns antropólogos contemporâneos, como Philippe Descola (Descola, 2005), Manuela Carneiro da Cunha (Cunha, 2009) e Eduardo Viveiros de Castro (Castro, 2002), que é preciso reconhecer outras concepções de natureza e cultura, não apenas aquelas pautadas pelo naturalismo, mas também as que seguem outros modelos (totemismo, animismo ou analogismo), ampliaremos sobremaneira as questôes envolvendo o corpo e sua relação com o mundo, a partir das possíveis linhas de continuidade e descontinuidade entre o homem e o ambiente. Há uma considerável ampliação das possibilidades de troca, de encontros, pois o arco de diversidade se amplia bastante a ponto de requerer outras epistemologias. No campo do teatro, Artaud avançou nessa direção (Quilici, 2004). Em Grotowski, podemos encontrar algumas chaves para compreender a relevância que ganha a relaçáo com a natureza no Teatro das Fontes.

O próprio Grotowski nomeou o campo em que desenvolveu suas pesquisas de Antropologia Teatral, como na cadeira que ocupou no Collège de France. O interesse presente em todos os momentos de seu percurso plural por práticas de origens culturais diversas ganhou especial destaque após a fase Parateatral (1969-1978), especialmente na fase denominada Teatro das Fontes (1976-1982), desdobrando-se 
até a Arte como Veículo, seu último projeto. Os escritos, registros e depoimentos disponíveis sobre essa passagem ao Teatro das Fontes sempre nos lembram que a experiência aí vivida resistia a uma exposição mais ampla, pois nela residia uma qualidade que nem sempre comportava traduçóes, uma vez que resultavam em teorias que despotencializavam a própria experiência. Interessa-nos, no entanto, seguir algumas pistas deixadas em textos publicados na época, ou mais recentemente, que permitem recolhermos elementos para pensarmos sobre como se deu e como se concebeu essa experiência em sua dimensão transcultural a partir de práticas corpóreas.

No início dos anos 1970, quando Grotowski começa a trabalhar nos projetos chamados parateatrais, a proposta de uma cultura ativa como um novo gênero de atividade criativa entra no universo das novas experimentaçóes. Podemos entender a formulaçáo cultura ativa a partir de uma característica da fase parateatral: teatro de participação, no qual todos se tornam ativos, em que não há um observador passivo. Proposição esta decorrente das profundas transformaçóes que se processaram no campo cultural a partir dos anos 1960. Mas, podemos entendê-la também no sentido de uma prática movente, que se transforma e é transformadora, relacional, inter-humana: como experiência. Foi na radicalizaçáo da proposta de encontro presente no Teatro Laboratório que se dissolveram os papéis convencionais do teatro, do ator e do espectador: "na estrada de uma cultura ativa", segundo Grotowski, estariam as atividades entre participantes e guias, profissionais e não profissionais, teatro e cultura de participação (Molinari, 2006, p. 27).

[...] onde tornava-se possível para aqueles que participavam o recíproco 'desarmar-se' das convençôes, das máscaras e dos papéis sociais, das hipocrisias e dos medos, e por consequência, o encontro entre seres humanos não divididos (Pollastrelli, 2006, p. 12).

O projeto Teatro das Fontes, que tem início enquanto ainda se davam experiências parateatrais, configura-se de outra forma: "Se o encontro inter-humano e o 'desarmar-se' recíproco e completo foram os elementos fundantes da prática parateatral, no Teatro das Fontes 'tratava-se das fontes de diferentes técnicas tradicionais, daquilo 'que precede as diferenças'” (Pollastrelli, 2006, p. 18). Aqui, explica a autora, ainda que em meio a um grande grupo, a abordagem era basicamente solitária, mesmo que coletiva em última instância. 
Ainda que a expressão cultura ativa esteja mais associada à fase parateatral, podemos entender que no Teatro das Fontes há um desdobramento de suas possibilidades, através de um ativo engajamento e conhecimento do corpo. Um trabalho direto com técnicas do corpo presentes em diferentes culturas que remetem a um campo que Grotowski vai denominar de técnicas fontes. Como técnicas de trabalho sobre si, relacionam-se também a uma experiência renovada da percepção e da relação do homem com a natureza: "[...] o que é natural (da natureza) remete ao que é da fonte, nascente. Qualquer um pode ser transportado pela luz da natureza. E a luz da natureza remete seu brilho ao originário, à fonte" (Grotowski, 2006, p. 80). Esse trabalho do homem sobre si mesmo e em relação à natureza esteve sempre entre as preocupaçóes mais profundas de Grotowski. A ponto de ter escrito que no Teatro das Fontes ele teria finalmente tornado público um trabalho que desenvolvera desde muito jovem (Grotowski, 2006, p. 87).

Como apresenta Carla Pollastrelli, os elementos concretos e estruturais do Teatro das Fontes são "[...] a composiçáo necessariamente transcultural do grupo de trabalho, expediçóes e exploraçóes, os princípios que comprovam a eficácia de uma ação" (Pollastrelli, 2006, p. 19). Partindo de elementos de diversas tradiçóes, trabalha-se com sua experiência direta. A pesquisa iria se dar em um eixo que incluía o corpo descondicionado de suas técnicas cotidianas e a procura de elementos compartilháveis que remetessem à dimensão transcultural, o que chamou de fonte das técnicas das fontes, a técnica antes da técnica tradicional. Não havia anulação das diferenças culturais, mas um trabalho que procurava ir além, ou aquém, das diferenças. Se a vida pode ser vista como uma espécie de sonho porque vivida em padrôes que se repetem, a abertura para as diferentes tradiçóes em sua diversidade "antropológica" possibilita um deslocamento que remete a outras possibilidades do homem em relação (Grotowski, 2006, p. 86).

"Eu estudei com pessoas pertencentes a diferentes contextos tradicionais o que Mauss descreveu como técnicas do corpo na vida cotidiana" (Grotowski, 1995, p. 22), ele diz. Para Marcel Mauss (Mauss, 2009) as técnicas cotidianas do corpo usualmente são a primeira diferenciação cultural, diz Grotowski, e coloca-se a pergunta: o que acontece quando as técnicas cotidianas do corpo, que são habituais em um círculo cultural definido, são suspensas? Quando são suspensas, que coisa aparece? Para ele, a primeira coisa que aparece 
é o descondicionamento da percepção (Grotowski, 2006, p. 91). O problema das barreiras culturais é de algo mais profundo que está inscrito nos corpos, não a língua, não a cultura, mas os medos, as formas de sentar, dormir, coisas inscritas no corpo.

Quando Grotowski apresentou seu projeto para o Collège de France, na década de 1990 (Grotowski, 1995), esse descondicionamento da percepção era tanto lembrado como técnica de trabalho quanto questionado em relação a possíveis riscos:

Eu observei que a suspensão temporária das técnicas cotidianas do corpo próprias ao contexto cultural do sujeito modifica seus modos de percepção. Em certos casos individuais, antes de colocar em trabalho os elementos práticos objetivos que provêm de uma tradição particular e que nós utilizamos num contexto transcultural, pode ser útil que o praticante passe por um estágio preparatório no qual ele altere as técnicas cotidianas do corpo que lhe são familiares. É, no entanto, uma questão muito delicada, porque a suspensão temporária de técnicas cotidianas do corpo (e que pode provocar uma mudança de modos de percepçáo) pode ter para algumas pessoas efeitos desestabilizadores (Grotowski, 1995, p. 22).

Grotowski se referia ao conceito de técnicas do corpo proposto por Marcel Mauss e também, segundo o autor, distinguia as técnicas cotidianas das técnicas rituais. Grotowski conduz sua investigação em uma direção que, partindo da percepção da técnica cotidiana e seu descondicionamento, busca o efeito da técnica ritual naquele que a faz, deixando-a provocar novas ressonâncias.

Para ele, havia também uma diferença entre as técnicas rituais orgânicas e as artificiais. Engenharia e jardinagem poderiam servir como metáforas para pensarmos as diferenças entre as práticas rituais artificiais e as práticas rituais orgânicas, ele diz. Enquanto uma prática ritual orgânica é fluida, contínua, enraizada no corpo ativo e ligada à atenção vigilante ao exterior, a artificial envolve composição muito rigorosa das posiçóes corporais, não identificação com o processo, náo-espontaneidade.

Talvez seja por isso que Grotowski, já em pleno desenvolvimento da Arte como Veículo, quando elaborou seu projeto para o curso de Antropologia Teatral do Collège de France, associaria a ideia de descondicionamento às técnicas rituais "artificiais" que buscam parar processos orgânicos (como respiraçáo, pensamento, movimento), orientadas para a "suspensão dos processos vitais" (Grotowski, 1995, p. 16). Seu interesse, no entanto, estava voltado para as técnicas 
enraizadas no fluxo dos impulsos, e que buscam ao mesmo tempo fluidez de comportamento e organicidade. Se náo era o descondicionamento, qual seria então o objetivo das práticas rituais orgânicas?, pergunta-se, "Digamos que se trate mais da transformação da energia cotidiana, pesada, mas plena de vida, às vezes violenta, ligada à sensualidade - em energias mais leves, poderíamos dizer sutis. $\mathrm{O}$ corpo é o veículo dessa passagem. O corpo, com seus impulsos, sua fluidez, sua organicidade" (Grotowski, 1995, p. 17).

No Teatro das Fontes, o grupo de trabalho era composto por praticantes tradicionais de diferentes culturas e religióes, como um índio huichol do México, hinduístas indianos, vodus do Haiti, mas também poloneses, americanos e europeus de vários países, judeus, cristãos ou agnósticos. As técnicas de fontes, no entanto, não eram compartilhadas.

O índio latino-americano, o japonês, o indiano trabalhavam juntos, mas não faziam nada que pertencesse a apenas uma tradição, buscavam uma ação evidente em sua consequência para todos os três. Quer dizer que funciona para todos os três apesar das diferenças de contexto cultural. O projeto é orientado em direção ao gênero de ação que "precedem as diferenças", e por este motivo abarca pessoas provenientes de tradiçóes e técnicas distantes umas das outras (Grotowski, 2006, p. 100).

Grotowski propunha, no entanto, experimentos que envolviam técnicas de tradição e técnicas individuais (Grotowski, 1980). As ações propostas pelos membros do grupo de trabalho e as de tradição eram simples como: a caminhada primordial, muito lenta, muito estruturada; os motions, sequência de posiçóes, movimentos orientados no espaço, extremamente precisa (presente até hoje no treinamento do Workcenter) ou The River, proveniente das tradiçóes de cantos e danças haitianos. Guiando-se por um certo silêncio (Grotowski, 2006), a imagem que reverbera dos textos às práticas remete ao movimento que é repouso (Grotowski, 2006).

[...] podemos estar acordados, alertas e totalmente em repouso: como se estivéssemos imersos em um sono sem confabulaçóes. Esse repouso é talvez o ponto crucial onde tem início diferentes técnicas das fontes. Temos portanto dois aspectos: movimento e repouso. Quando nos movemos e quando somos capazes de um caminho nas técnicas do corpo da vida cotidiana, então o nosso movimento se torna um movimento de percepção. Se pode dizer que o nosso movimento é ver, ouvir, sentir; o nosso movimento é percepção (Grotowski, 2006, p. 96-97). 
Quanto às fontes, é preciso dizer que existe o homem que precede as diferenças (Grotowski, 2006, p. 90). Talvez em Peter Brook, um dos principais interlocutores de Grotowski, possamos encontrar mais uma pista. Para Brook, "[...] o corpo humano não contém somente suas raízes nacionais, regionais. Em sua vida orgânica, ele é um terreno comum à humanidade inteira" (Borie, 2006, p. 11). Segundo Borie, Brook entende que só podemos trabalhar no teatro para além das raízes particulares à medida que o corpo, enquanto tal, se torna fonte de trabalho.

A organicidade, o que é? É viver em harmonia com as leis naturais, mas em nível primário. Nosso corpo é um animal. Não se pode esquecer disso. Não digo: somos animais. Digo: nosso corpo é um animal. [...] Claro, é possível prolongar a vida da organicidade lutando contra os hábitos adquiridos, contra o treinamento da vida ordinária, rompendo, eliminando os clichês de comportamento, e regressando à reação primária, antes da reação complexa. $\mathrm{O}$ fundamental, parece-me, é sempre fazer preceder a forma pelo que tem que a preceder, por um processo que leva à forma (Grotowski, 1997a, p. 121).

O que Grotowski fala sobre os cantos tradicionais vibratórios, que se tornaram centrais no Drama Objetivo e na Arte como Veículo, ajuda-nos a entender o que se investigava entáo. Através dos cantos tradicionais buscava-se engajar a vida interior de forma nova, através de novas ressonâncias.

[...] o que é surpreendente é o fato de que este tipo de canto, com os impulsos que estão ligados a eles (sob a condição de serem cantados com uma melodia e um tempo-ritmo precisos e corretos) pode detonar na pessoa que canta um processo "psicofísico", mesmo que esta não conheça a linguagem original do canto, e náo saiba nada de seu conteúdo verbal (Grotowski, 1995, p. 19).

Grotowski trabalhava muitas vezes com práticas que guardavam uma relação com a tradição, mas que transgrediam as institucionalizaçôes. Uma pulsão viva, não institucionalizada, de transmissão de um conhecimento pela via da performance, da prática corpórea e vocal. Pistas para o acesso a territórios inexplorados em certas culturas, mas cultivados por outras, na maior parte das vezes em seus contextos liminares. É interessante observar como estáo presentes cantos de tradiçóes diaspóricas, de pessoas deslocadas, tiradas de seu lugar: como se fosse uma saudade de voltar ao lugar de origem, uma saudade de casa. 
As várias açóes que se desenrolaram, a modalidade do silêncio e da solidão "ao lado dos outros", na natureza, abriram em certos momentos as portas da percepção, permitiram obter uma visão mais vasta da existência: "no mundo vivo, o corpo vivo" (Pollastrelli, 2006, p. 19).

Na base de todo esse trabalho há uma proposta de Ecologia que avança para uma compreensão transcultural.

Na polaridade entre tradição e pesquisa Grotowski dá vida à tentativa concreta de criar um novo equilíbrio naquela que define "civilização da colonização": "colonização do corpo, do planeta, de si mesmo, da vida, dos sentidos" (Pollastrelli, 2006, p. 19).

Schechner descreve os movimentos da pesquisa de Grotowski da seguinte maneira: "O Trabalho sobre si levou do teatro ao Parateatro; a busca sobre o que é transcultural e essencial levou do Parateatro ao Teatro das Fontes; destilar essas fontes em um comportamento estruturado levou do Drama Objetivo à Arte como Veículo" (Schechner, 1997, p. 213).

Podemos entender que a cultura ativa proposta por Grotowski no contexto das pesquisas parateatrais é "transcultural", ao pensarmos que ela reconhece que estamos em um espaço "entre", em um tecido de relaçóes no qual a alteridade é nossa singularidade e que a abertura para o outro é a base da ação transcultural. Ela opera nesse registro, porque visa justamente radicalizar a experiência do encontro: quando define seu teatro como encontro, quando sai do teatro em busca de aprofundar a experiência do encontro, quando propóe as experiências parateatrais como encontros inter-humanos. A dimensão transcultural ganha ainda uma ampliação de sentido quando cria um projeto como o Teatro das Fontes, proporcionando o encontro com as bases de outras técnicas do corpo, que são fruto do acúmulo de conhecimento de muitas geraçóes em diferentes culturas, e que vão além da experiência inter-humana para, na solidão de cada indivíduo, ainda que em coletivo, proporcionar uma experiência que tem início com a abertura da percepção: os sentidos e seus objetos, a circulação da atenção, a corrente vislumbrada quando se está em movimento, o corpo vivo no mundo vivo (Pollastrelli, 2006, p. 19).

Há algo na natureza do encontro que é a possibilidade de transformação. A cultura viva: em movimento. A prática deslocada não é a prática original, locada. O corpo modificado pelo encontro também não é mais o mesmo corpo do desconhecimento. Há uma ampliação e amplificação da experiência. Uma potencialização da 
condição que compartilhamos na alteridade e que se constituirá em nova alteridade. Como nos lembra Georges Banu: "[...] é para se refazer que partimos e buscamos outro lugar" (Banu, 2006, p. 79).

Nossa singularidade é a presentificação de uma experiência única (histórica, cultural, vivencial), que, se nos configura e nos torna únicos e se é um valor em si, ao mesmo tempo esse nosso contorno é nosso limite, nossa limitação. Mas nosso movimento permanente é o de nos transformarmos, nos movermos através dos encontros, das formas como nos afetamos, coletivizar, borrar permanentemente esses contornos.

A intensificação dos processos de troca entre as artes vivas e as práticas rituais no contexto internacional coloca a questão do significado desses deslocamentos de práticas nos dois campos e em contextos culturais distintos. O que acontece quando a prática segue nos corpos que a experimentaram para outros territórios, para outros contextos? Aquelas práticas de tradiçóes institucionalizadas - ritualizadas - podem questionar a operação de migração. Questionam esse deslocamento como perda de fundamento. O Teatro das Fontes e as etapas subsequentes da investigação de Grotowski, o Drama Objetivo e a Arte como Veículo, no entanto, constituíram e constituem um campo privilegiado para se investigar essas questóes na medida em que as colocam sob novas perspectivas.

Em uma mesa redonda em Caen, Mario Biagini ${ }^{2}$ propôs uma interessante metáfora para pensar o tema do teatro como uma arte do encontro. Quando alguém se referiu às raízes culturais como arestas postas no caminho do encontro, ele disse que sentia que suas raízes estavam mais voltadas para o ar do que para a terra: como raízes aéreas. As raízes aéreas não são fixas na terra, nem circunscritas por um lugar, uma geografia. O ar é compartilhado, respiramos e expiramos o mesmo ar.

Encontrar formas performáticas que se transmitem como conhecimento - conhecimento corporificado - é buscar no encontro a perspectiva de experienciar uma forma cultural diferente da própria, abrindo-se para um caminho e um mapa novos, em relação à experiência de si, do outro e do espaço. Outras formas de pensar-se, perceber-se, relacionar-se, outras possibilidades de circuitos, conexóes, fluxos, pensar-se em movimento mais do que pensar-se em identidade. Talvez para se chegar ao mesmo lugar. 


\section{Notas}

${ }^{1}$ Conferência realizada por Mario Biagini em dezembro de 2011, Shangai Theatre Academy, Shangai (China). Anotaçóes do autor.

${ }^{2}$ Participação de Mario Biagini em Mesa-redonda "Formes et enjeux de la rencontre dans les arts scéniques contemporains", com Pipo Delbono e cantoras do grupo de Sidi Larbi Cherkaoui, IMEC, Caen, 24 mar. 2012. Anotaçóes do autor.

\section{Referências}

BANU, Georges. Le Retour, Défi du Fils Prodigue. Alternatives Théâtrales, Bruxelles, n. 89, p. 79, 2006.

BORIE, Monique. L'ailleurs, Tremplin pour un Language Renouvelé. Alternatives Théâtrales, Bruxelles, n. 89, p. 10-15, 2006.

CASTRO, Eduardo Viveiros. A Inconstância da Alma Selvagem e Outros Ensaios de Antropologia. Sáo Paulo: Cosac Naify, 2002.

CUNHA, Manuela Carneiro da. Cultura com Aspas e Outros Ensaios. São Paulo: Cosac Naify, 2009.

DESCOLA, Philippe. Par-delá Nature et Culture. Paris: Gallimard, 2005.

ECO, Umberto. Ils Recherchaient des Licornes. In: PICHON, Alain de; SOW, Moussa.

Le Renversement du Ciel. Paris: CNRS Éditions, 2011. P. 309-325.

FÉRAL, Josette. El Interculturalismo y los Problemas de Recepción. In: FÉRAL, Josette.

Teatro, Teoría y Práctica: más allá de las fronteras. Buenos Aires: Galerna, 2004. P. 129164.

GROTOWSKI, Jerzy. Em Busca de um Teatro Pobre. Rio de Janeiro: Ed. Civilização Brasileira, 1971.

GROTOWSKI, Jerzy. Ipotesi di Lavoro. Sipario, ano XXXV, n. 404, p. 12 a 15, $1^{\circ}$ trimestre de 1980.

GROTOWSKI, Jerzy. Oriente/Occidente. Máscara, ano 3, n. 11-12, p. 62-68, 1993.

GROTOWSKI, Jerzy. Projet d'Enseignement et de Recherches: anthropologie théâtrale. Projeto apresentado para candidatura de Grotowski ao Collège de France. Arquivo de Mario Biagini. Cedido à pesquisadora Tatiana Motta Lima, 1995.

GROTOWSKI, Jerzy. Era como un Volcán. In: PANAFIEU, Bruno (Org.). Gurdieff. Venezuela: Editorial Ganesha, 1997a. P. 117-138.

GROTOWSKI, Jerzy. Holiday [Swieto]: the day that is holy. In: SCHECHNER, Richard; WOLFORD, Lisa. The Grotowski Sourcebook. London/New York: Routledge, 1997b. P. 215-225.

GROTOWSKI, Jerzy. Theatre of Sources. In: SCHECHNER, Richard; WOLFORD, Lisa. The Grotowski Sourcebook. London/New York: Routledge, 1997c. P. 252-270. 
GROTOWSKI, Jerzy. Holiday e Teatro delle Fonti. Florença: La Casa Usher, 2006.

GROTOWSKI, Jerzy. Da Companhia Teatral à Arte como Veículo. In: FLASZEN, Ludwik; POLLASTRELLI, Carla (Org.). O Teatro Laboratório de Jerzy Grotowski - 1959-1969. São Paulo: Ed. Perspectiva/Ed. Sesc, 2007. P. 226-243.

LIMA, Tatiana Motta. Palavras Praticadas: o percurso artístico de Jerzy Grotowski, 1959-1974. São Paulo: Editora Perspectiva, 2012.

MAUSS, Marcel. Sociologie et Anthropologie. Paris: PUF, 2009.

MOLINARI, Renata M. Diario dal Teatro delle Fonti - Polonia 1980. Florença: La Casa Usher, 2006.

PAVIS, Patrice. O Teatro no Cruzamento de Culturas. São Paulo: Ed. Perspectiva, 2008.

PAVIS, Patrice. The Intercultural Performance Reader. London/New York: Routledge, 1996.

POLLASTRELLI, Carla. Prefazione. In: GROTOWSKI, Jerzy. Holiday e Teatro delle Fonti. Florença: La Casa Usher, 2006.

QUILICI, Cassiano Sidow. Antonin Artaud: teatro e ritual. São Paulo: Annablume, 2004.

RICHARDS, Thomas. Trabalhar com Grotowski sobre as Açóes Físicas. São Paulo: Ed. Perspectiva, 2012.

RICHARDS, Thomas. The Edge-point of Performance. Pontedera: Workcenter of Jerzy Grotowski, 1995.

SCHECHNER, Richard. Introduction to part II, Paratheatre, 1969-78, and Theatre of Sources, 1976-82. In: SCHECHNER, Richard; WOLFORD, Lisa. The Grotowski Sourcebook. London/New York: Routledge, 1997. P. 207-214.

Fernando Antonio Mencarelli é professor Titular do Departamento de Fotografia, Teatro e Cinema e da Pós-Graduação em Artes da Escola de Belas Artes da Universidade Federal de Minas Gerais. Pesquisador do CNPq e diretor teatral.

E-mail: fernandomencarelli@gmail.com

Recebido em 25 de outubro de 2012 Aprovado em 01 de dezembro de 2012 